- This study describes a multifactorial analysis of factors associated with dental erosion in a random sample of 1,149 Leicestershire children.

- Positive associations were found between erosion and decay experience and with drinking fruit juice or fizzy pop.

- The presence of calculus or eating fruit other than apples or citrus fruit reduced the chances of erosion.

- No association was found between erosion and gingival health, dental cleanliness, orthodontic anomaly, a history of asthma, eating apples and citrus fruit, eating chips with tomato sauce or vinegar, chocolate, sweets or drinking tea, coffee or fruit squash.

\title{
A multifactorial analysis of factors associated with dental erosion
}

\author{
C. R. Dugmore ${ }^{1}$ and W. P. Rock ${ }^{2}$
}

\begin{abstract}
Objectives This study prospectively examines the relationship of possible aetiological factors to the presence of tooth erosion in a cohort of children.

Patients and methods A random sample of 1,753 children was examined at age 12 and 1,308 of the same children were re-examined at age 14 years. The children were asked to complete questionnaires on both occasions, 1,149 subjects gave usable replies. The erosion index used was based upon the 1993 Survey of Children's Dental Health. Results were analysed using logistic regression.

Results At age 12 significant positive associations were found between erosion and decay experience (odds ratio $[O R]=1.48$ ), drinking fruit juice $(\mathrm{OR}=1.42)$ or fizzy pop $(\mathrm{OR}=1.59-2.52$, depending on amount and frequency). The presence of calculus (OR 0.48) or eating fruit other than apples or citrus fruit (OR 0.48) reduced the chances of erosion. High consumption of carbonated drinks increased the odds of erosion being present at 12 years by $252 \%$ and was a strong predictor of the amount of erosion found at age 14 .

Conclusions Of the factors investigated, a history of dental caries and a high consumption of carbonated drinks were most closely related to the presence of dental erosion. The risk of erosion bore a strong relationship to the amount and frequency of carbonated drink consumption.
\end{abstract}

It is only relatively recently that tooth erosion has been recognized as presenting a dental health problem in children. In 1993, the prevalence of erosion was reported as part of the national survey of Children's Dental Health in England and Wales ${ }^{1}$ for the first time. Fifty per cent of 6-year-olds were found to have erosion and in $23 \%$ of children it had progressed into dentine. Thirty two per cent of 14-year-old children had erosion of the permanent dentition, with dentinal involvement present in $2 \%$.

The three main types of non-carious loss of dental hard tissue are attrition, abrasion and erosion. ${ }^{2}$ Attrition implies removal of tooth surface due to movement of teeth against one another, pos-

${ }^{1}$ Senior Community Dentist, Melton Rutland and Harborough NHS Trust ${ }^{2 *}$ Reader in Orthodontics, The University of Birmingham, The School of Dentistry

"Correspondence to: Dr W. P. Rock, Department of Orthodontics, School of Dentistry, St Mary's Row, Birmingham B4 6NN

Email:w.p.rock@bham.ac.uk

\section{Refereed paper}

Received 17.12.02; Accepted 7.5.03

doi:10.1038/sj.bdj.4811041

๑ British Dental Journal 2004; 196: 283-286 sibly in association with an abrasive substance. ${ }^{3}$ Attrition produces hard, shiny, smooth flattening of the affected tooth surface. Abrasion is tooth wear caused by agents introduced into the mouth. ${ }^{3}$ The most frequent type of abrasion is that produced at the necks of the teeth by inappropriate tooth brushing, ${ }^{4}$ although similar lesions may be produced by abfraction. Erosion is superficial loss of dental hard tissue by a chemical process that does not involve bacteria. ${ }^{5}$ The acids responsible for erosion are not produced by the oral flora but arise from dietary, intrinsic (gastric acid reflux) or occupational sources. The characteristic features of erosive lesions include a polished appearance, cupping on incisal edges and cusps and loss affecting labial surfaces. The loss of tooth surface is disproportionate to the age of the subject.

The term toothwear ${ }^{6}$ is a useful generic term to describe tooth surface loss since it does not prejudge the aetiology of a particular case in which one or more processes may occur. For example accelerated abrasion may take place at a surface already demineralized by erosion. ${ }^{7}$ In adults, differential diagnosis becomes difficult in this type of situation, ${ }^{4}$ although in children it is acknowledged that the major cause of toothwear is erosion. ${ }^{8}$

Tooth erosion is a multi-factorial condition and the causative factors may be divided into extrinsic and intrinsic types, appropriately represented by a VENN diagram (Figure 1). ${ }^{9}$

Extrinsic causes include environmental factors, medicaments, lifestyle and diet. The most important environmental cause of erosion is exposure to acid fumes or aerosols at work. ${ }^{10}$ This is not relevant to erosion in children. Medicaments may influence tooth erosion by several mechanisms. Firstly damage may be produced directly by the acidity of the drug; Nunn et al. ${ }^{11}$ found the $\mathrm{pHs}$ of ten medicines prescribed for children with renal disease all to be well below 5.5, the $\mathrm{pH}$ at which acid dissolution of enamel begins. A medicament may also cause xerostomia, which tends to increase consumption of carbonated drinks or it may reduce salivary flow and thereby lessen the protective effects of saliva for the teeth.

Several studies have examined a possible association between erosion and inhaled medication used to treat asthma. It has been suggested that such aerosols may have a direct effect on the tooth or may pose an indirect risk due to xerostomia produced by the beta 2 agonist content of drugs such as terbutaline and salbutamol. Inhalers which deliver these medicaments may be used up to four times a day over long periods and since 10\% of children in Britain are affected by asthma, ${ }^{13}$ erosion produced by associated medica- 


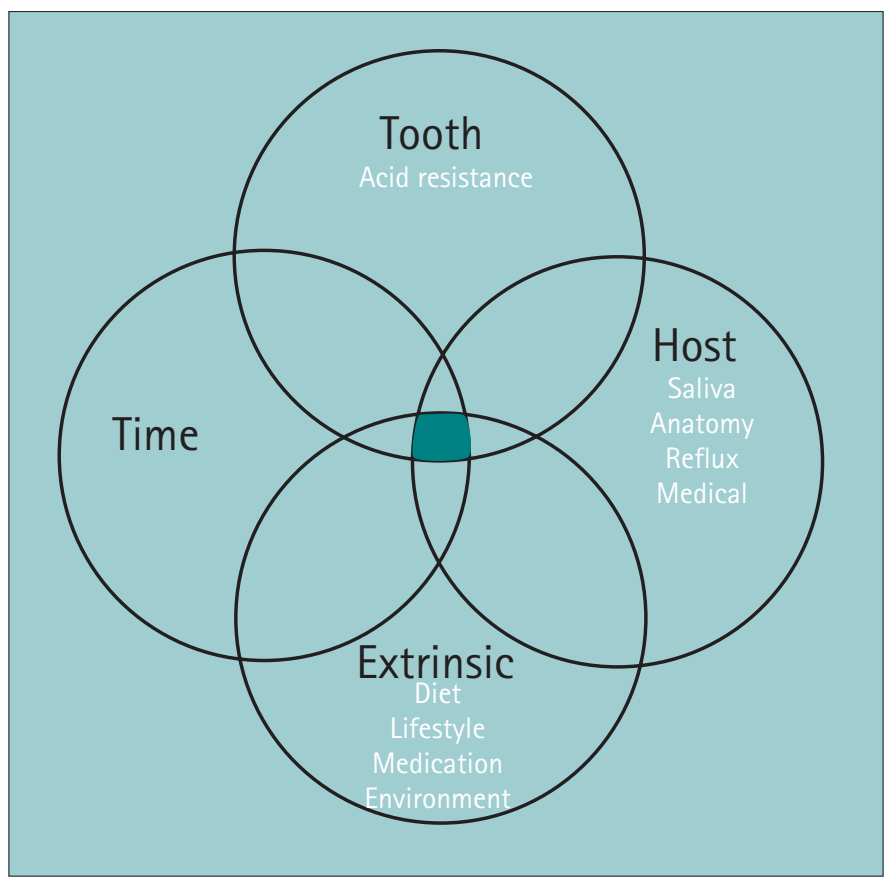

Fig.1 Multi-factorial aetiology of dental erosion: the overlapping factors may all be required to some extent to produce severe erosion, shown as the dark area in the centre. ${ }^{9}$

tion could pose a significant population-wide dental health problem. However the evidence for such an association is unclear. Although Shaw et al. ${ }^{14}$ reported that children with asthma were at an increased risk of developing erosion, the NDNS survey of 4-18year-olds ${ }^{15}$ yielded no clear association between asthma and dental erosion.

Aspects of lifestyle that have been associated with erosion are the consumption of low $\mathrm{pH}$, sugar-containing sports drinks ${ }^{16}$ and infant fruit juices, which have pHs ranging from 3.6-4.1 when diluted. ${ }^{17}$

Diets that may pose an erosive risk to the teeth are those that include an unusually high consumption of citrus fruits, ${ }^{18}$ fruit juice ${ }^{19}$ and carbonated soft drinks. There has been particular interest in carbonated drinks since there has been a great increase in their consumption by children over the last few decades. ${ }^{15,20}$

Intrinsic tooth erosion may occur if gastric acid reaches the mouth due to vomiting, regurgitation or gastroesophageal reflux disease (GORD). ${ }^{21}$ In anorexic or bulimic individuals the frequency of vomiting episodes may be associated with erosion experience. ${ }^{22}$

\section{Indices for recording tooth erosion}

After reviewing many indices that had been used previously to record erosion, Smith and Knight devised a Tooth Wear Index (TW1) ${ }^{23}$ to record all three main types of toothwear irrespective of aetiology. This index was based on visual examination of 128 tooth surfaces per subject and the recoding of features on a 5-point scale from $0=$ No loss of enamel surface characteristics, to $4=$ Complete loss of enamel with exposure of secondary dentine or pulp. The TW1 was used in the National Survey of Children's Dental Health in modified form, ${ }^{1}$ with only erosion on the maxillary incisors being assessed.

\section{AIMS OF THE PRESENT STUDY}

The aim of the present study was to investigate associations between tooth erosion and some possible aetiological factors in a sample of 12-year-old children.

\section{MATERIALS AND METHODS}

A random sample of 1,753 children aged 12 years was drawn from all state maintained schools in Leicestershire on the basis of including every fifth child on the relevant school register. Boys and girls were sampled separately to ensure representative samples. Two years later 1,308 children were re-examined. Part of the investigation involved the completion of a questionnaire by the children at the 12 year examination. This was designed to investigate aspects of oral health behaviour, dietary habits and a history of gastric reflux or asthma (Table 1). A shorter questionnaire, concentrating upon drinks consumption was used at the 14 year examination. Unfortunately 159 questionnaires were not properly filled in so that the final analysis was on the basis of 1,149 subjects.

Before data collection was commenced, ethical approval was obtained from Leicestershire Health Authority and letters of explanation were sent to all parents. Examinations were carried out in the schools in a standard manner using a Daray 4000 dental light. The teeth were not cleaned or dried routinely, if necessary gross debris was removed using gauze. The erosion index used was based upon that from the 1993 Survey of Children's Dental Health, ${ }^{1}$ with erosion being diagnosed on the basis of visual examination and the use of a CPITN probe which was run over the tooth surface to check for loss of enamel surface characteristics.

Codes were as follows:

Depth: $0 \quad$ Normal enamel

1 Loss of surface enamel characteristics

2 Loss of enamel exposing dentine

3 Loss of enamel and dentine with pulp exposure

9 Assessment could not be made

\section{Area: $0 \quad$ Normal}

1 Less than one third of surface involved

2 Between one and two thirds of surface involved

3 More than two thirds of surface involved

9 Assessment could not be made

The teeth examined for erosion included the incisors and first permanent molars. Buccal and lingual surfaces were examined on incisors and buccal, occlusal and lingual surfaces on molars.

Other data were recorded in addition to erosion status as follows:

- An orthodontic assessment of treatment need was based on an abbreviated form of the IOTN. ${ }^{24}$ Photographs 8-10 from the AC of IOTN and grades 4 and 5 of the DHC were used to indicate definite need for treatment.

- Dental cleanliness was recorded using the Plaque Index. ${ }^{25}$

- Gingival health was assessed using criteria based on those used in the 1993 National Survey of Children's Dental Health. ${ }^{1}$

- Calculus was recorded as present or absent on visual examination.

- Caries and fillings were recorded to produce a DMF score according to standard criteria. ${ }^{1}$

- Ethnicity.

- Social deprivation was scored from postcodes, according to the Townsend Deprivation Scale. ${ }^{26}$

\section{Calibration}

The examiner (CRD) was trained and calibrated in the recording of all the survey data used in the present study as an experienced member of the BASCD and National Adult, Childrens and NDNS dental health studies. Before the present study, a reproducibility exercise was carried out, involving examination of around $12012-$ year-olds and 120 14-year-olds on two occasions one week apart.

\section{Statistical methods}

Multifactorial analysis of coded data was carried out using Minitab version 13.31 to investigate possible associations between 


Table 1 Questions asked at age 12
1. How many times do you clean your teeth each day?
2. How often do you go to the dentist?
3. Do you eat apples, oranges or grapefruit, other fruit, chips with vinegar or
tomato sauce, chocolate or sweets?
4. Do you ever get a nasty/acidic taste in your mouth after eating?
5. Do you suffer from asthma and use an inhaler regularly?
6. How many glasses/cans of the following do you drink each day? Water, milk,
tea/coffee, chocolate, squash, fruit juice, fizzy pop.
7. Are your teeth sensitive to hot and cold food and drink?

Table 2 Erosion scores in 12- and 14-year-old boys and girls

\begin{tabular}{llllllll}
\hline Erosion level & Absent & \multicolumn{3}{c}{ Enamel loss } & \multicolumn{2}{c}{ Dentine exposed } & Total \\
& No. & $\%$ & No. & $\%$ & No. & $\%$ & \\
\hline 12 years & 504 & 43.9 & 618 & 53.8 & 27 & 2.3 & \\
14 years & 399 & 34.7 & 648 & 56.4 & 102 & 8.9 & 1149
\end{tabular}

suspected aetiological agents and the presence of erosion. Firstly data records were recoded to produce a suitable binary record and multiple logistic regression was performed with the results adjusted for all variables, both significant (listed) and non significant (not listed in tables).

Quantatiative data analysed using paired and unpaired $t$-test where appropriate.

Chi-squared test was used to test the strength of associations between independent sample proportions.

\section{RESULTS}

\section{Reproducibility study}

Kappa values of 0.80 and 0.67 were obtained for erosion depth and erosion area respectively in the 12-year-old children. The corresponding values for the 14 -year-olds were 0.84 and 0.71 respectively. All indicate a good level of intra-examiner agreement.

\section{Main study}

Full records were available for 1,149 subjects after both the 12 and 14 year examinations. There were 585 boys and 564 girls. The predominant ethnic groups were Caucasian 909 (79.1\%) and Asian 206 (17.9\%). At the 12-year-old examination 645 (56.1\%) subjects had erosion. Two years later the figure was 750 (65.3\%) (Table 2). At the second examination only $34.7 \%$ of the children had mouths completely free of the signs of tooth erosion.

The associations between aetiological factors and the presence and incidence of erosion were examined using logistic regression. Factors that showed a significant association with tooth erosion at age 12 were: experience of dental decay; calculus; eating fruit other than apples or citrus fruit; and drinking either fruit juice or fizzy pop (Table 3). No significant associations were found regarding dental cleanliness; gingival health; orthodontic anomalies; asthma; eating apples, chips with tomato sauce or vinegar, citrus fruit, sweets or chocolate; or drinking coffee, chocolate or squash.

Odds ratios for the variables that proved to have significant associations with erosion are also shown in Table 3. The most powerful positive associations with erosion experience related to carbonated drinks. Any consumption increased the chances of erosion by $59 \%$ whilst drinking four or more glasses per day produced a 252\% increase. The presence of calculus and eating fruits other than apples and citrus fruit reduced the chances of erosion by around 50\%.

In order to test whether it was possible to predict future erosion on the basis of existing information, a second analysis was carried out, based upon a comparison of the data collected at age 12 with the presence of erosion at age 14 as the dependent variable (Table 4). Experience of caries and fizzy pop consumption increased the chances of future erosion by around 50\%, whilst an orthodontic anomaly, the presence of calculus or consumption of fruits other than apples or citrus types appeared to confer a protective effect.

\begin{tabular}{|c|c|c|c|c|}
\hline & $\mathrm{p}$ & $\begin{array}{l}\text { odds ratio } \\
\text { Lower }\end{array}$ & & $\begin{array}{l}95 \% \mathrm{Cl} \\
\text { Upper }\end{array}$ \\
\hline Decay & 0.002 & 1.48 & 1.15 & 1.90 \\
\hline Calculus & $<0.001$ & 0.48 & 0.37 & 0.62 \\
\hline Fruit other than apples and citrus & $<0.001$ & 0.48 & 0.36 & 0.66 \\
\hline Fruit juice & 0.011 & 1.42 & 1.08 & 1.85 \\
\hline Fruit juice $3+$ per day & 0.002 & 1.83 & 1.25 & 2.69 \\
\hline Fizzy pop & 0.002 & 1.59 & 1.18 & 2.13 \\
\hline Fizzy pop $3+$ per day & $<0.001$ & 2.08 & 1.49 & 2.91 \\
\hline Fruit juice $4+$ per day & $<0.001$ & 2.52 & 1.69 & 3.75 \\
\hline
\end{tabular}

The above results are adjusted for all the listed factors and for the following non-significant factors; gingival health, dental cleanliness, orthodontic anomaly, a history of asthma, eating apples and citrus fruit, chips with tomato sauce or vinegar, chocolate, sweets, or drinking tea, coffee or fruit squash.

Table 4 Logistic regression table for significant factors measured at 12 years of age possibly affecting the prevalence of tooth erosion in 14-yearold children

\begin{tabular}{lrccc}
\hline Predictor & $P$ & odds ratio & \multicolumn{2}{c}{$95 \% \mathrm{Cl}$} \\
& & & Lower & Upper \\
\hline Orthodontic anomaly & 0.003 & 0.68 & 0.52 & 0.88 \\
Decay experience & 0.001 & 1.55 & 1.20 & 2.02 \\
Calculus & $<0.001$ & 0.44 & 0.34 & 0.57 \\
Fruit other than apples and citrus & 0.002 & 0.61 & 0.45 & 0.84 \\
Fizzy pop & 0.015 & 1.46 & 1.08 & 1.97 \\
Fizzy pop 3+ per day & $<0.001$ & 2.16 & 1.46 & 3.18 \\
Fizzy pop 4+ per day & 0.001 & 2.23 & 1.41 & 3.54 \\
\hline
\end{tabular}

The above results are adjusted for all the listed factors and for the following non-significant factors; gingival health, dental cleanliness, a history of asthma, eating apples and citrus fruit, chips with tomato sauce or vinegar, chocolate, sweets, or drinking tea, coffee or fruit squash.

Again high consumption of fizzy pop was the principle association with erosion, the danger increasing by around 50\% for each additional intake each day.

Data on beverage consumption at age 14 revealed that only carbonated drinks had a significant association with tooth erosion (Table 5). Fizzy pop drinking at this age increased the chance of tooth erosion by 220\%; if four or more glasses were drunk each day the risk increased by 513\%. At age 12, 76.5\% of children reported fizzy pop drinking, by age 14, 92.3\% replied positively. At age $12,40.9 \%$ of the children drank three or more glasses per day, by age 14 the proportion had increased to $45 \%$.

\section{DISCUSSION}

Data from 1,149 children were analysed in this study. A total of 1,753 children were examined from 62 schools at age 12 years, and 1,308 re-examined at 14 . Losses were sustained as children in 39 schools changed educational establishment at the age of 14 years, and not all attended their designated upper schools. In addition six schools were in the process of closing during the study. Questionnaires were fully completed by 1,149 subjects enabling their inclusion in the analysis. The gender and ethnic composition of the 1,149 sample remained the same as the 1,753 sample so that the losses did not appear to have affected the distribution of the sample.

Saliva analysis was not included because positive consent would have been required for its collection, compromising the validity of the random nature of the sample due to increased refusals. In addition the cost of analysis would have been prohibitive.

Factors that were found to have a significant positive association with tooth erosion at 12 years included decay experience, and the consumption of fruit juice and carbonated drinks (Table 3). Greater frequency of fruit juice and pop consumption increased the likelihood of erosion. This effect was more marked for pop than fruit juice. Both fruit juice and carbonated drinks have been shown to have low pHs and high titratable acidity ${ }^{17,27}$ and frequent con- 


\begin{tabular}{|c|c|c|c|c|}
\hline \multirow[t]{2}{*}{ Predictor } & \multirow[t]{2}{*}{$P$} & \multirow[t]{2}{*}{ Odds ratio } & \multicolumn{2}{|c|}{$95 \% \mathrm{Cl}$} \\
\hline & & & Lower & Upper \\
\hline Fizzy pop & $<0.001$ & 2.21 & 1.47 & 3.31 \\
\hline Fizzy pop $3+$ per day & $<0.001$ & 2.82 & 1.87 & 4.24 \\
\hline Fizzy pop 4+ per day & $<0.001$ & 5.13 & 2.74 & 9.62 \\
\hline
\end{tabular}

The above results are adjusted for all the listed factors and for all factors mentioned as nonsignificant in the lists below Tables 3 and 4 .

sumption places teeth at serious risk of erosion (odds ratio of 1.53) in 2-5-year-olds. ${ }^{28}$ Calculus and eating fruit other than apples and citrus fruit, which at this age is most probably bananas, had a significant negative association with tooth erosion. The conditions that promote the formation of calculus include an excess of salivary calcium ions. This may alter the balance of calcium ions. High levels of calcium ions in saliva at the tooth interface at low $\mathrm{pH}$ may be sufficient to decrease or block the effects of potential erosive agents and also to aid re-mineralisation. ${ }^{29}$

Data collected at 12 years were used to predict future erosion at age 14 and revealed similar associations to those found at 12 years. There was no significant association with fruit juice, which may be explained by a decrease in its consumption at this age. However, having an orthodontic anomaly decreased the chances of having erosion from a non-significant $18 \%$ at 12 years to a significant $32 \%$ at 14 years. A reduction in erosion may possibly be a result of teeth in a non aligned arch decreasing the clearance rate and increasing pooling of saliva around teeth, and by so doing, increasing its protective effects. ${ }^{30,31}$ It has been suggested that the anatomy and physiology of the mouth, including interproximal spaces, occlusion and soft tissue anatomy may influence the retention or clearance or liquids in the mouth. ${ }^{32-34}$

The multifactorial analysis completed by Al-Malik et al. ${ }^{28}$ also found a significant association between erosion and frequency of fizzy drink consumption, with an odds ratio of 1.46, but this was for 2-5-year-olds. The demonstration of increased risk is not the same as the identification of aetiology and attempts to show a causal relationship between risk factors and erosion have failed, although the sample sizes were small. ${ }^{35-37}$ Other studies have found statistically significant differences between the mean number of carbonated drinks consumed and the levels of erosion. ${ }^{4}$ The most important factor in developing erosion from acidic drinks appears to be whether the drink is consumed at all, and if so, if the frequency of uptake is more than three times a day, then the risks are increased considerably. ${ }^{38}$

The association of pop consumption and tooth erosion was strongest in the 14-year-olds. The odds ratios increased again with frequency of intake, with the 95\% confidence intervals indicating that some 14-year-olds will be nearly 10 times more likely to have tooth erosion, when drinking pop four or more times each day. The level of consumption was found to increase between age of 12 and 14 from 76.5\% to 92.3\%. Furthermore, 41\% of 12-year-olds doubled their chance of experiencing erosion compared with those who did not drink carbonated drinks, and 45\% of 14-year-olds had nearly three times the chance.

The present study provides no evidence of an association between tooth erosion and dental cleanliness; gingival health; asthma; gastric reflux and various commonly consumed foods and drinks. However, the consumption of a diet that causes dental decay in children also appears to increase the chances of tooth erosion. The presence of calculus and an orthodontic anomaly may help to lessen the impact of erosion, however the threat posed to adolescent teeth by the consumption of carbonated drinks in particular is considerable and appears to increase with age and with the frequency of consumption.

\section{CONCLUSIONS}

A history of dental caries and a high consumption of carbonated drinks showed the greatest correlations with dental erosion. The risk of erosion bore a strong relationship to the amount and frequency of carbonated drink consumption.

1. O'Brien M. Children's dental health in the UK, 1993. London: HMSO

2. Miller W D. Experiments and observations on the wasting of tooth tissue variously designated as erosion, abrasion, chemical abrasion, denudation etc. Dent Cosmos 1907: XLIX: 1-23; 109-124; 225-247.

3. Eccles J D. Tooth surface loss from abrasion, attrition and erosion. Dent Update 1982; Aug: 373-381.

4. Millward A, Shaw L, Smith A J, Rippin J W. The distribution and severity of tooth wear and the relationship between erosion and dietary constituents in a group of children. Int J Paed Dent 1994; 4: 151-157.

5. Ten Cate J M, Imfeld T. Dental erosion, a summary. Eur J Oral Sci 1996; 104: 241-244.

6. Smith B G N, Robb N D. The prevalence of toothwear in 1007 dental patients. J Oral Rehab 1996; 23: 232-239.

7. Davies W B, Winter PJ. The effect of abrasion on enamel and dentine after exposure to dietary acid. Br Dent J 1980; 148: 253-256.

8. Millward A, Shaw L, Smith A. Dental erosion in 4-year-old children from differing socio-economic backgrounds. J Dent Child 1994; July-Aug; 263-266.

9. Shaw L, Smith A J. Dental erosion - the problem and some practical solutions. Br Dent J 1998; 186: 115-118.

10. Ten Bruggen Cate H J. Dental erosion in industry. Br J Ind Med 1968; 25: 249-266

11. Nunn J H, Sharkey I, Coulthard M. Acidic medicines and the implications for oral health of renal patients. J Dent Res 1999; 78: 1083, Abs 389.

12. Kargul B, Tanboga I, Ereneli S, Karakoc F, Dagli E. Inhaler medicament effects on saliva and plaque $\mathrm{pH}$ in asthmatic children. J Clin Ped Dent 1998; 22: 137-140.

13. McDerra E J, Pollard M A, Curzon M E. The dental status of asthmatic British school children. Ped Dent 1998; 20: 281-287

14. Shaw L, Al-Dlaigan Y H, Smith A. Childhood asthma and dental erosion. J Dent Child 2000; 67: 102-106.

15. Gregory J, Lowes. National Diet and Nutrition Survey: young people aged 4-8. Vol 1. London: HMSO, 2000.

16. Meurman $\mathrm{J} H$, Harkonen $M$, Naveri $H$ et al. Experimental sports drinks with minimal dental erosion effect. Scand J Dent Res 1990; 98: 120-128.

17. Smith A J, Shaw L. Baby fruit juices and tooth erosion. Br Dent J 1987; 162: 65-67.

18. Dunne S M. Aetiology and management of dentine hypersensitivity. Dent Prac 1995 33: $1-4$

19. Lussi A, Schaffner M, Hotz P, Suter P. Dental erosion in a population of Swiss adults. Comm Dent Oral Epidemiol 1991; 19: 286-290.

20. Watt R G, Dykes J, Sheiham A. Preschool children's consumption of drinks: implications for dental health. Comm Dent HIth 2000; 17: 8-13.

21. Kitchin L, Castell D 0. Rationale and efficacy of conservative therapy for gastroesophageal reflux disease. Archs Internat Med 1991; 151: 448-454.

22. Milosovic A, Slade P D. The orodental status of anorexics and bulimics. Br DentJ 1989; 167: $66-70$.

23. Smith B G N, Knight J K. An index for measuring the wear of teeth. Br Dent J 1984 156: 435-438.

24. Brook P H, Shaw W C. The development of an index of orthodontic treatment priority. Europ J Orthodont 1989: 11: 309-320.

25. Löe $H_{1}$ Silness J. Periodontal disease in pregnancy II. Correlation between oral hygiene and periodontal condition. Acta Odont Scand 1964; 22: 121-135.

26. Townsend $\mathrm{P}$, Phillimore $\mathrm{P}, \mathrm{Beattie} A$. Health and deprivation inequality and the North London: Croon Helm, 1988.

27. Chadwick R G, Practitioner evaluation of an erosive potential data sheet. J Dent Res 2000; 79 : 1197 (Abs 210)

28. Al-Malik M, Holt R D, Bedi R. The relationship between erosion, caries and rampant caries and dietary habits in preschool children in Saudi Arabia. Int J Paediatr Dent 2001; 11: 430-439.

29. Robinson C. Saliva. Dent Digest. 2000; 1: 1-3

30. Weatherell J A, Robinson C, Nattress B R. Site specific variation in the concentrations of substances in the mouth. Br Dent J 1989; 165: 289-292.

31. Shaw $L$, Smith A J. Comparison of rates of clearance of glucose from various sites following drinking with a glass feeder cup and straw. Med Sci Res 1993; 21: 617-619.

32. Thomas A K. Further observations on the influence of citrus fruit juices on human teeth. NYStDentJ 1957; 23: 424-430.

33. Lagerlof $F$, Dowes $C$. The volume of saliva in the month before and after swallowing. $J$ Dent Res 1984; 63: 618-624.

34. Weatherell J A, Strong N, Robinson $C$, Nakagaki $H$, Ralph J P. Retention of glucose in the oral fluid at different sites in the mouth. Caries Res 1989; 20: 399-405.

35. Bartlett D W, Coward PY, Nikkah C, Wilson R F. The prevalence of toothwear in a cluster sample of adolescent schoolchildren and its relationship with potential explanatory factors. Br Dent J 1998; 184: 125-129.

36. Williams D, Croucher R, Marcenes W, O'Farrell M. The prevalence of dental erosion in the maxillary incisors of 14 year old school children living in Tower Hamlets an Hackney, London UK. Int Dent J 1999; 49: 211-216.

37. Deery $C$, Wagner $M L$, Longbottom $C$, Simon $R$, Nugent $Z J$. The prevalence of dental erosion in a United States and a United Kingdom sample of adolescents. Ped Dent 2001; 2: 505-510.

38. O'Sullivan E A, Curzon M E J. A comparison of acidic dietary factors in children with and without dental erosion. J Dent Child 2000; 67: 186-192. 